\title{
ТРАНСФОРМАЦИЯ АДМИНИСТРАТИВНОГО УПРАВЛЕНИЯ В КОНТЕКСТЕ СОВРЕМЕННЫХ ПРИНЦИПОВ МЕНЕДЖМЕНТА
}

В статье анализируются особенности трансформации административного управления в сложных административных системах. Охарактеризованы современные принципы нормотворческой деятельности в системе публичного администрирования. Проанализированы современные сложные административные системы управления, приведены направления научного анализа таких систем на основе использования принципов менеджмента. Подана авторская трактовка понятий орган власти, уровни управления, территориальное управление. Разработаны и систематизированы теоретические основы возникновения, становления и развития сложных управленческих систем. Доказано на основе исследования, что именно публичноправовое нормирование поведения субъектов и объектов управления, которое осуществляется с помощью организационно-правового регулирования, способно обеспечить согласованность и целенаправленность их деятельности, ориентированной на удовлетворение общественных потребностей и интересов, которые объективно существуют на конкретном этапе общественного развития. Акцентирован тот факт, что европейский опыт организации администрирования управленческих систем свидетельствует об актуализации нормотворческой составляющей публичного администрирования.

В статье особое внимание уделено современным парадигмам развития управленческой науки. В частности, сделан акцент на целесообразности трансформации административных принципов в контексте реформирования публичного управления в Украине. Это связано, в первую очередь, с имеющейся необходимостью систематизации принципов деятельности властных структур. На этой основе с позиций системного анализа доказано, что публичное администрирование предусматривает функционирование универсального организационно-правового механизма выявления, согласования и реализации общественных потребностей и интересов на основе использования различных правовых средств. Это, в свою очередь, предусматривает формирование комплекса субъективных прав и обязанностей участников общественных процессов, перевод их связей и отношений в конкретные правоотношения.

\footnotetext{
${ }^{1}$ Vitalii Bashtannyk, dr nauk administracji publicznej, profesor Katedry Prawa i Integracji Europejskiej Dniepropietrowskiego Regionalnego Instytutu Zarządzania Państwem (filia Narodowej Akademii Zarządzania Państwem przy Prezydencie Ukrainy), e-mail: vbashtannyk @gmail.com

${ }^{2}$ Tetyana Stadnichenko, doktorant, Katedra Prawa i Integracji Europejskiej Dniepropietrowskiego Regionalnego Instytutu Zarządzania Państwem (filia Narodowej Akademii Zarządzania Państwem przy Prezydencie Ukrainy), e-mail: ddepartment-lawmail.ru
} 
Ключевые слова: децентрализация, государственное управление, интегрированные системы государственного управления, связи с общественностью, менеджмент.

\section{1. ВВЕДЕНИЕ}

Европейские интеграционные процессы 70-90 XX в. способствовали возникновению принципиально новых институтов власти и административных механизмов согласования позиций и выработки общих подходов ведущих государств по решению региональных и глобальных проблем. В таких условиях государственное управление в процессе реформирования приобретает новые характерные признаки, повышается его субъектность, усиливаются интегративные характеристики управления. Именно поэтому современный процесс реформирования государственного управления обусловлен становлением открытой административной системы, в которой постоянно происходит гармонизация принципов, инструментов, форм и методов центрального, территориального и локального управления, и одновременно, - процесс собственного развития приобретает институт делегирования полномочий в соответствии с феноменом делегированного управления как императива общей политики в рамках Европейского Союза. На этом базируется новое направление в науке публичного управления - исследование теоретико-методологических основ реформирования государственного управления в условиях европейских интеграционных процессов в контексте усиления регулирующего воздействия таких процессов на управленческие механизмы национальных государств. Ведь европейский интеграционный процесс как проявление общемировых тенденций в современных условиях характеризуется как системное измерение социально-экономического и политического развития стран Европы.

Актуальность проблематики исследования интегрированных подходов менеджмента и государственного администрирования обусловлена тем фактом, что европейская интеграция представляет собой реализацию общепризнанных концепций управления в пределах ЕС - «единого европейского дома», «экономической интеграции», «устойчивого развития» и другие. В этих обстоятельствах Украина как демократическое, социальное, правовое государство нуждается в таких организационных формах, средствах, институтах и механизмах организации государственного управления, которые в целом отвечают базовым характеристикам менеджмента. И в то же время такие организационные конструкции должны соответствовать национальным традициям публичного управления, получать общественное признание, регулироваться постоянными правовыми нормами и развиваться в контексте общецивилизационного процесса гуманизации властных отношений.

Кроме того, актуальность нашего исследования определена тем фактом, что реформирование государственного управления требует сочетания общих процессов оптимизации деятельности органов власти: совершенствования института государственной службы, службы в органах местного самоуправления и специализированной служебной деятельности работников органов власти (в соответствии с понятием «публичная служба»); формирования новой интегративной региональной политики страны через децентрализацию управленческих отношений, развития политической системы Украины. То есть, в соответствии со стратегией 
устойчивого развития «Украина-2020», предложенной Президентом Украины П.Порошенко, актуализируется углубление исследований реформирования системы государственного управления в контексте интеграционных процессов по следующим направлениям: государственное управление как система общественных отношений; обеспечение прав и свобод человека как измерение гуманизации управления; политический и административный аспекты государственного управления; конституционно-правовые основы государственного управления в контексте наднациональных интеграционных процессов; анализ и адаптация зарубежного опыта трансформации государственного управления; развитие регионального и отраслевого управления в соответствии с требованиями законодательства ЕС.

Целью данной статьи выступает анализ состояния системы общественных отношений в сфере публичного (государственного) управления и разработка на этой основе концептуальных основ трансформации управления на основе принципов менеджмента. Проблемной сферой данного исследования является создание современных, адаптированных к вызовам современного общества управленческих моделей, способных сохранять устойчивость при нестандартных внешних управляющих воздействий.

Актуальные исследования базовых принципов государственного управления в системе внутренней и внешней политики Украины, зарубежного опыта конституирования управленческой деятельности в системе интеграционных процессов и определение путей его внедрения в Украине дают основания утверждать, что участие в интеграционных процессах является основным фактором становления в нашей стране новых экономических отношений, формирования демократических институтов, обеспечения прав и свобод человека. Именно поэтому целью и приоритетным направлениям исследования реформирования государственного управления является определение понятия и содержания государственного управления в системе наднациональных интеграционных процессов, установления постоянных динамических тенденций развития национального государства в условиях интеграционных процессов. Такая цель достигается с учетом наработки науки государственного управления, права, политологии, что в результате формализует обновление демократической концепции управления, адаптации такой концепции в условиях переходного общества с тем, чтобы она могла быть использована в качестве теоретической основы при подготовке нового и уточнении положений действующего законодательства. Вместе с тем, в статье ставится задача осуществить исследовании эффективных механизмов национального управления в контексте рассмотрения его как элемента системы наднационального управления в пределах полномочий наднациональных административных институтов, а также в определении таких принципов надгосударственного управления, которые могут быть внедрены в отечественной практике для оптимизации государственной политики администрирования и нормотворчества, как направления совершенствования государственно-управленческой деятельности в целом.

Степень разработанности темы. В условиях углубления наднациональных интеграционных процессов собственно государственное управление, государственно-управленческие отношения, государственно-управленческая деятельность приобретают новые характерных признаков, усиливается 
субъектность такой деятельности, выделяются ее принципы и направления. Фактически, речь идет о формировании открытой системы публичного управления как сложной административной системы, в рамках которой происходит постоянный процесс гармонизации принципов, механизмов и методов территориального управления с усилением инструментов и механизмов делегирования полномочий, построения многоуровневых, вертикально интегрированных структур управления.

Проблематику государственного управления в контексте развития механизмов современного администрирования исследовали украинские ученые В.Аверьянов, В.Бакуменко, Р.Войтович, В.Голубь, С.Дубенко, Ю.Кальниш, В.Князев, С.Кравченко, В.Литвин, В.Луговой, Н.Нижник, С.Серёгин, Г.Сытник, О. Скакун, В.Тертичка, В. Шаповал, а также зарубежные ученые Г.Атаманчук, В.Афанасьев, Л.Бальцерович, К.Бельский, Ж.Бодуен, И.Василенко, К.Ващенко, В.Воллес, К.Гаджиев, Ж.Зиллер, А.Моравчек, Н.Нагент, М.Паренти, Г. Райт и др. Достаточно широкий спектр научных работ дал возможность системно проанализировать этапы становления современной модели управления на центральном и региональном уровне, определить общие тенденции формирования принципов публичноадминистративного менеджмента, определить общие тенденции формирования управленческих отношений на общегосударственном и региональном уровне, рассмотреть базовые этапы становления системы государственного управления и на этой основе предложить интеративную методологию исследования реформирования государственного управления.

С позиций реализации в Украине общих принципов публичного управления, административных правил и процедур, характерных для Европейского административного пространства, следует акцентировать внимание на общих и специальных принципах администрирования. Среди общих принципов управления следует выделить и принцип конкретности, смысл которого заключается в том, что необходимо изучать конкретные процессы управления, сравнивать их с соответствующими законами и закономерностями общественного развития, смотреть как последние действуют, оказываются по конкретным обстоятельствам, и делать правильные выводы для практики. В условиях реформирования украинского общества особое значение приобретает совершенствование, рационализация и формирование четкого механизма правового регулирования государственноуправленческих отношений ${ }^{3}$. В.Мартыненко на основе эмпирических и теоретикометодологических подходов к исследованию сущности общественных трансформаций в условиях глобализации проанализированы концептуальные методологические основы теории государственного управления, раскрыты принципы деятельности государственной власти ${ }^{4}$.

Основу современных исследований процессов реформирования управления составляют работы европейских исследователей. Так А.Милворд указывает, что в процессе реформирования нецелесообразно акцентировать внимание на добровольной передачи государством своих суверенных полномочий новосформированной транснациональной элите. По мнению этого исследователя,

\footnotetext{
${ }^{3}$ Н.Р. Нижник, Государственно-управленческие отношения в демократическом обществе : монографія, Основи, К. 1995, с. 65-67.

4 В.М. Мартиненко, Державне управління: шлях до нової парадигми (теорія та методологія): монографія, Вид-во ХарРІ НАДУ «Магістр», Х. 2003, с. 113.
} 
интеграция является выгодной тогда, когда речь идет об объединении ресурсов с целью достижения общих целей и решения общих проблем, что является особенно актуальным из-за развития современных глобализационных процессов ${ }^{5}$. С.Гофман еще в конце 1960-х гг., указывал, что стремление государств к интеграции определяется стремлением функционировать в ситуации как можно большей определенности на национальном уровне без давления внешних структур ${ }^{6}$. Внешнее влияние на процессы реформирования могут оказывать и наднациональные субъекты. Так, Е.Моравчик считает, что институциональная политика ЕС непосредственно определяет влияние на процесс реформирования, и в принципе может изменять цели реформирования ${ }^{7}$.

Направлениями реформирования государственного управления в Украине в соответствии с европейскими принципами публичного администрирования выступают:

1) перспективы внедрения зарубежного опыта (в том числе, опыта Республики Польша) интеграционного сотрудничества в практику государственного управления в Украине; комплекс критериев определения кратко-, средне - и долгосрочных приоритетов развития многосторонних и двусторонних отношений со странами-членами ЕC, а также в формате межгосударственных образований на постсоветском пространстве; методология определения зависимости эффективности государственного управления от состояния системы политического консенсуса в стране по национальной интеграционной стратегии ${ }^{8}$;

2) особенности становления и организационно-правовые основы управленческой деятельности в сложных административных системах, концептуальное утверждение административно-правовых средств обеспечения прав и свобод граждан в системе наднациональных интеграционных процессов, направления оптимизации классификационной системы признаков гармонизации международного и национального законодательства относительно осуществления управленческой деятельности ${ }^{9}$;

3) закрепление принципа наднационализма в системе государственноуправленческих решений, реальные достижения в формировании направлений разработки надгосударственных механизмов управления интеграционными процессами, основные направления государственного управления в сфере регионального сотрудничества; дальнейшее развитие получило определение сущности, цели и реализации общих политик EC, нормативных и фактических оснований их применения на национальном почве .

\footnotetext{
${ }^{5}$ A.S. Milward, The European Rescue of the Nation State, Routledge, London 2000, c. 71.

${ }^{6}$ S. Hoffmann, Obstinate or Obsolete? The Fate of the Nation State and the Case of Western Europe, [in:] B. Nelsen, A. Stubb, The European Union. Readings on the Theory and Practice of European Integration, 2nd ed., Macmillan Press Ltd., London 1998, c. 157-172.

${ }^{7}$ A. Moravcsik, Preferences and Power in the European Community. A Liberal Intergovernmentalist Approach, Journal of Common Market Studies”31/4 (1993), c. 482-498.

${ }^{8}$ Nowe partnerstwo dla spójnosci konwergencja konkurencyjnosc wspólpraca. Trzeci raport na temat spójności gospodarczej $i$ społecznej, Режим доступу: www/europa.eu.int/comm/regional_policy/sources/docoffic/ official/reports/cohesion3/cohesion3_pl.htm. - Назва з екрану.

${ }^{9}$ A. Olechowskij, Four Premises for the Polish Strategy in the European Union, „The Polish Foreign Affairs Digest" 9/4 (2003), c. 23-35.
} 


\section{2. ОСНОВНАЯ ЧАСТЬ ИССЛЕДОВАНИЯ}

На данном этапе развития стран постсоветского пространства особое значение приобретает тенденция тесной взаимосвязи административной реформы и региональных интеграционных процессов, внедрение инновационных механизмов общественно-политических отношений, систематизированных, в том числе, и в условиях членства стран в ЕС. При этом наблюдаем выделение самостоятельных политических подходов к проблеме управления в наднациональных интеграционных процессах - федерализма (федеративной модели управления с постепенным переходом к федеративному (конфедеративному) устройству надгосударственного образования), функционализма (деполитизации интеграционного процесса, формирования функциональной модели управления, при которой надгосударственные структуры формируются по функциональному признаку), неофункционализма (создание системы надгосударственных институтов управления, делегирование части национального суверенитета и властных полномочий странами-членами на уровень институтов ЕС. Следовательно, фактически речь идет о базовом принципе «европейского административного менеджмента» - принципа наднационализма, его воплощении в международноправовых отношениях, реализации концепции «сообщества безопасности» (определение характера интеграционных процессов через взаимоотношения, складывающиеся между отдельными личностями и социальными группами).

Развивая положения административного менеджмента, стоит заметить, что достижение высокой эффективности и качества любого вида управленческой деятельности заключается в повышении эффективности и качества правового обеспечения такой деятельности. Именно публично-правовое нормирование поведения субъектов и объектов управления, которое осуществляется с помощью организационно-правового регулирования, способно обеспечить согласованность и целенаправленность их деятельности, ориентированной на удовлетворение общественных потребностей и интересов, которые объективно существуют на конкретном этапе общественного развития. Европейский опыт организации администрирования управленческих систем свидетельствует об актуализации нормотворческой составляющей публичного администрирования.

Публичное управление проходит сейчас очередной этап трансформации, характеризуется как внутренними характеристиками (политический, исторический, институциональный и т.д.), так и внешними - взаимодействие с ЕС, и в зависимости от этих процессов речь идет о переходе к постиндустриальному обществу, формировании трансформационных факторов в системе государственного управления. В условиях новой парадигмы общественных отношений инструменты и механизмы публичного (государственного) управления меняются, так же изменяются задачи такого управления. На процесс управления влияют усиленные социальные риски, нестабильные социальные связи, рост социальной мобильности, глобализация экономики, потребность в нововведениях. Именно этим и объясняется отказ от устоявшихся форм управленческой деятельности и наработки модели управления нового типа - New Public Management (NPM) ${ }^{10}$, однако сохраняется и

\footnotetext{
${ }^{10}$ Blackwell Handbook of Global Management, ред. M.L. Maznevski, J. McNett, Blackwell Pub., Malden, MA, 2004, p. 234-236.
} 
традиционное деление составляющих государственно-управленческого механизма на институциональную, административную и процедурную составляющую .

В общем, традиционной ошибкой широкого внедрения зарубежных методик модернизации таких больших систем как государственное управление, местное самоуправление и т.д. является простое копирование технологий административных реформ, безоговорочная реализация в национальной практике государственного управления таких концепций как «политические сети», «Good governance» и т.д. ${ }^{11}$. Впрочем, концепция «нового государственного управления» имеет существенные отличия, среди которых усиление надзорной функции центрального уровня, децентрализация и усиление мобильности территориальных составляющих, обеспечение контроля и подотчетности, рационализация управления человеческими ресурсами, обеспечения конкуренции и отбора, и одновременно - повышение качества государственного регулирования, транспарентность как ключевой принцип в деятельности органов власти.

Тенденцией общественного развития современного Украинского государства является ориентация государственного управления на социально-экономическую эффективность и демократическое взаимодействие с обществом. Начиная с 1997г., тезис об административной реформе как важное условие экономического роста и социального развития актуализировался многочисленными нормативными актами, регламентирующими развитие системы государственной службы. Вместе с тем, существуют многочисленные вызовы для системы государственного управления, присущие большинству современных государств. Во-первых, система исполнительной власти до сих пор закрыта для общества. Во-вторых, привлечение населения и общественных структур к процессу разработки, принятия и осуществления политических решений реализуется органами власти далеко не полностью. Именно поэтому эффективность государственного управления и качество публичных услуг в Украине находятся на одном уровне со странами, намного уступающими ей по уровню экономического развития и качества человеческого потенциала. Рациональным решением является системный анализ и эффективное внедрение положительных практик государственного управления и функционирования государственной службы в других странах. Это даст возможность определить, какие из имеющихся вариантов реформирования и в какой степени могут быть использованы в нынешних условиях перманентных реформ, а также, по возможности, учесть допущенные в этих странах ошибки и просчеты и избежать их.

Сравнение отечественных реалий с зарубежным опытом позволит лучше понять логику эволюции национальной модели административной реформы и определить пути ее обновления и внедрения. Либеральная концепция «нового публичного управления», лежащая в основе европейской административной реформы, а также конкретные меры реформы противоречат характеру тех политических стратегий, которые используются политической властью. В свою очередь, успешная административная реформа требует в качестве условия фундаментальной модернизации публичного управления глубинной трансформации политической системы на основе открытости и реальной состязательности. Для этого следует

\footnotetext{
${ }^{11}$ The new handbook of organizational communication: advances in theory, research, and methods, ред. F.М. Jablin, L.L. Putnam, Sage Publications, Thousand Oaks, CA - London - New Dehli 2001, c. 6.
} 
выявить наиболее эффективные и релевантные в условиях Украины теории и концепции реформирования государственного управления и государственной службы, определить результаты и перспективы дальнейшей административной реформы.

Открытая система публичного управления определяет качественно новое направление исследований науки управления - исследование политического и административного аспектов государственного управления в наднациональных интеграционных процессах. Ведь государство как социально-организационный институт представляет собой систему взаимодействия многочисленных социальных сообществ и государственно-управленческого аппарата ${ }^{12}$. При этом «опережающее состояние» государственного управления проявляется в инновационном векторе развития государственного управления, субъектно-объектной компоненте взаимовлияния, демократическом характере становления системы властнопартийного взаимодействия. В условиях реформирования украинского общества особое значение приобретает также формирование четкого механизма правового регулирования государственно-управленческих отношений.

Современные проблемы трансформации общественных отношений в Украине, разработка новых механизмов реализации положений Конституции Украины, проведение административной реформы в Украине внесли и продолжают вносить существенные изменения в содержание государственно-управленческой деятельности, формирования и реализации государственно-служебных отношений. Именно поэтому на данном этапе развития общества целью административноправового регулирования является совершенствование форм и методов управленческой деятельности, установление и регламентация таких взаимоотношений граждан и государственных институтов, когда каждому человеку должны гарантироваться реальное соблюдение и охрана прав и свобод, а также эффективная защита этих прав и свобод в случаях их нарушений. Собственно, публичное администрирование предусматривает функционирование универсального организационно-правового механизма выявления, согласования и реализации общественных потребностей и интересов на основе использования различных правовых средств, формирования комплекса субъективных прав и обязанностей участников общественных процессов, перевод их связей и отношений в конкретные правоотношения. Поскольку достижение высокой эффективности и качества любого вида управленческой деятельности заключается в повышении эффективности и качества правового обеспечения такой деятельности, то именно публично-правовое нормирование поведения субъектов и объектов управления, которое осуществляется с помощью организационно-правового регулирования, способно обеспечить согласованность и целенаправленность их деятельности, ориентированной на удовлетворение общественных потребностей и интересов, которые объективно существуют на конкретном этапе общественного развития.

Целесообразность трансформации административных принципов в контексте реформирования публичного управления (в основном на региональном уровне) в Украине связана, в первую очередь, с имеющейся необходимостью рассмотрения систематизации принципов деятельности властных структур, поскольку в

\footnotetext{
12 А. Баштанник, Організаційно-правові засади управління в складних адміністративних системах: європейський досвід та Украӥна, А.Баштанник, В.Баштанник, „Право України” 2007/11, с. 153-157.
} 
современных условиях понимание государственно-управленческих отношений и государственно-управленческой деятельности в широком подходе интегрирует понятие публичного управления ${ }^{13}$. Вместе с тем, сейчас актуализируется потребность имплементации европейских принципов как в теорию, так и в практику государственно-управленческой деятельности, прежде всего, на уровне территориальной общины (базовый уровень) и регионального управления (высший уровень в системе самоуправления и базовый - в системе исполнительной власти). В условиях перманентного политического реформирования системы власти в Украине возникла необходимость в системном подходе к гармонизации европейского и национального правового обеспечения деятельности самоуправляющихся структур $^{14}$.

Почти 25 лет реформирования системы публичного администрирования в Украине значительно изменили роль самоуправляющихся структур в обществе, однако до сих пор самоуправление сохраняет статус общественного института, инкорпорированного к механизму государственно-управленческих решений, и статус де-факто подчиненного субъекта через имеющиеся механизмы делегирования полномочий, бюджетный процесс, налоговую политику и тому подобное. При этом декларируемые как основные европейские принципы организации управления выступили как лозунги государственной политики, однако реальные изменения не были проведены. С позиций европейского права следует определить общую систему принципов управления, присущую всем уровням управления. Это принципы: народовластия; верховенства закона; распределения и взаимодействия власти; разграничения полномочий органов центрального, регионального и локального уровня; гласности и открытости; приоритета и гарантированности прав личности; плановости; разграничения функций и полномочий в системе власти.

Нормативного закрепления требует урегулирование проблемы соотношения «самоуправляющихся» и «делегированных» полномочий местного самоуправления, способствовующих укреплению правовой и организационной самостоятельности местного самоуправления; финансовому, материальному росту ресурсного обеспечения выполнения органами местного самоуправления делегированных им отдельных полномочий органов исполнительной власти. При этом следует законодательно определить принципы, условия и порядок делегирования отдельных полномочий органов исполнительной власти, формы контроля за исполнением делегированных полномочий, ответственность органов исполнительной власти и местного самоуправления, их должностных лиц за неисполнение или ненадлежащее исполнение делегированных полномочий. Для территориального уровня власти законом должен быть установлен перечень полномочий, которые не могут быть удалены, переданы или делегированы к другому уровню.

$\mathrm{C}$ позиций определения направлений оптимизации государственноуправленческой деятельности на региональном уровне в организационной сфере возникают и требуют собственного решения две проблемы. Первая связана с

13 О.Э. Бессонова, Общая теория институциональньх трансформаций как новая картина мира, „Общественные науки и современность” 2006/2, с. 130-142.

${ }^{14}$ О.Л. Валевський, Державне управління як інструмент впровадження реформ в Україні [Текст], О.Л. Валевський, В.А. Ребкало, „Аналітика і влада” 2012/6, с. 139-144. 
созданием системы взаимодействия центральных органов государственной власти с органами местного самоуправления. Такое взаимодействие необходимо прежде всего самой центральной власти в контексте административной, политической, жилищно-коммунальной, бюджетной, налоговой и социальной реформ. Системные реформы невозможны без активного участия в их проведении органов местного самоуправления, муниципальных служащих, широких слоев населения. Второй проблемой является необходимость совершенствования организации местного самоуправления, в том числе, методическое обеспечение органов местного самоуправления по вопросам структурной организации управления социальным развитием, муниципальным хозяйством и местными финансами, а также подготовка муниципальных управленческих кадров. Эта задача может быть решена путем создания системы непрерывного обучения должностных лиц местного самоуправления, путем использования принципов менеджмента в публичной деятельности.

Процессы децентрализации, внедрение принципа субсидиарности, повышение уровня требований человека к разнообразию и качеству получаемых им услуг, увеличение его влияния на власть обусловили поиск новых моделей построения и организации деятельности самоуправляющихся институтов с учетом современной парадигмы управления.

Стоит отметить, что проблематика административного реформирования и в Украине, и за рубежом все чаще исследуется не в «узком» ракурсе административно-иерархического или менеджериального типа, a c учетом методологии «public administration» (публичного управления, правда, широкоупотребляемым в последнее время является перевод «публичное администрирование»), объединяющая деятельность органов государственного управления, государственной власти, местного самоуправления и различных общественных структур, которые участвуют в реформировании государственного аппарата, его взаимоотношений с обществом. Постоянство в методологию публичного управления внесла теория общественного выбора. Однако полной аналогии между политической и рыночной системами провести нельзя, ведь объектная база таких понятий разная. Впрочем, предложенная методология позволяет выявлять интересные закономерности, формировать инновационные подходы к социализации управления через восприятие социальных институтов на уровне субъектов рыночных отношений.

Важно указать на компоненты объектной сферы публичного управления, которыми в таком формате выступают общественные отношения, формирующиеся:

- в процессе государственного управления экономической, социальнокультурной и административно-политической сферами, а также реализации полномочий исполнительной власти, делегированных государством органам местного самоуправления, общественным организациям и некоторым другим негосударственным институтам;

- в процессе деятельности органов исполнительной власти и органов местного самоуправления, их должностных лиц по обеспечению реализации и защиты в административном порядке прав и свобод граждан, предоставление различных административных (управленческих) услуг;

- в процессе внутренней организации и деятельности аппаратов всех государственных органов, администраций государственных предприятий, 
учреждений и организаций, а также в связи с прохождением государственной службы или службы в органах местного самоуправления;

- при применении мер административного принуждения, включая административную ответственность, в отношении физических и юридических лиц;

- в связи с реализацией юрисдикции административных судов и восстановления нарушенных прав граждан.

При этом концепция «Нового публичного управления» выступает в роли идеологемы реформирования государственного управления, в рамках которого уменьшается демократизм, однако управление направлено на повышение экономической эффективности государственного управления и борьбу с бюрократизмом. Определенной особенностью реформирования здесь выступает консенсусный характер выработки особо значимых решений; сравнительно медленные темпы осуществления программы реформ; широкое привлечение общественности к обсуждению характера общественных трансформаций; преобладание личностного фактора над административным. Административная реформа при этом носит в основном не административный, а политикоадминистративный характер. Именно достижения общественного консенсуса относительно целей и способов реформирования административной системы могло бы стать важным условием успешной реализации реформы в нашей стране.

\section{3. ВЫВОДЫ}

На основе проведенного в статье исследования целесообразно сделать следующие выводы. Государственную власть вполне мотивировано следует детерминировать как инструмент обеспечения существования государства, достижения ее целей. При этом государственная власть способна влиять на общественные процессы, поведение отдельных социальных групп с помощью специальных органов и учреждений как составных частей единого механизма государственной власти. Определение комплекса управления как сознательного, организованного и регулирующего воздействия на собственную общественную и групповую жизнедеятельность, осуществляемое непосредственно или косвенно через государство, самоуправления, партии, фирмы, позволяет детерминировать современное публичное управление как целенаправленное, организационное, системное воздействие на жизнедеятельность общества. Определяющим субъектом государственного управления в пределах личных и общественных взаимоотношений следует считать орган власти. Орган власти (государства) составная часть государственного аппарата, группа лиц или лицо, наделенное законодательно определенными властными полномочиями для выполнения задач и функций государства.

С позиций государственного управления заметим, что в контексте системы исполнительной власти орган власти - организационно самостоятельный элемент государственного аппарата (механизма государства), который наделен четко очерченным объемом полномочий (компетенции) в соответствии с возложенными на него задачами и функциями, состоит из структурных подразделений и должностей, занимающих государственными служащими, и отнесен Конституцией и законами Украины, указами Президента Украины в систему органов исполнительной власти. Такое определение органа власти через призму 
современных принципов менеджмента позволяет сделать вывод об актуальности формирования устойчивой модели государственного управления на региональном уровне на основе четкого определения и законодательного закрепления распределения полномочий и обязанностей между органами исполнительной власти и местного самоуправления. На этапе реформирования необходимо сохранить крепкую вертикаль государственной власти, которая призвана обеспечить действенность системы управления и стабильность национальной экономики. К объективным свойствам реформирования государственного управления относятся также системность, единство, непрерывность, стабильность и управляемая гибкость, когда власть выступает формой выражения общественных интересов наряду с обеспечением взаимосвязи между отдельными интересами и эффективным управлением.

\section{ЛИТЕРАТУРА}

[1] Нижник Н.Р., Государственно-управленческие отночения в демократическом обществе : монографія, Основи, К. 1995, 180 с.

[2] Мартиненко В.М., Державне управління: шлях до нової парадигми (теорія та методологія) : монографія, Вид-во ХарРІ НАДУ «Магістр», Х. 2003, 218 с.

[3] Milward A.S., The European Rescue of the Nation State, Routleadge, London 2000, 453 p.

[4] Hoffmann S., Obstinate or Obsolete? The Fate of the Nation State and the Case of Western Europe, [in:] B. Nelsen, A. Stubb, The European Union. Readings on the Theory and Practice of European Integration, 2nd ed., Macmillan Press Ltd., London 1998, c. 157-172.

[5] Moravcsik A., Preferences and Power in the European Community. A Liberal Intergovernmentalist Approach, „Journal of Common Market Studies” 31/4 (1993), c. 482 498.

[6] Nowe partnerstwo dla spójnosci konwergencja konkurencyjnosc wspólpraca. Trzeci raport na temat spójności gospodarczej $i$ społecznej, Режим доступу: www/europa.eu.int/comm/regional_policy/sources/docoffic/official /reports/cohesion3/cohesion3_pl.htm. - Назва з екрану.

[7] Olechowskij A., Four Premises for the Polish Strategy in the European Union, „The Polish Foreign Affairs Digest" 9/3 (2003), c. 23-35.

[8] Blackwell Handbook of Global Management, ред. M.L. Maznevski, J. McNett, Blackwell Pub., Malden, MA, 2004, 476 p.

[9] The new handbook of organizational communication: advances in theory, research, and methods, ред. F.M. Jablin, L.L. Putnam, Sage Publications, Thousand Oaks, CA - London New Dehli 2001, 911 p.

[10] Баштанник А., Організаційно-правові засади управління в складних адміністративних системах: європейський досвід та Украӥна, А. Баштанник, В. Баштанник, „Право України" 2007/11, с. 153-157.

[11] Бессонова О.Э., Общая теория институциональных трансформаций как новая картина мира, „Общественные науки и современность” 2006/2, с. 130-142.

[12] Валевський О.Л., Державне управління як інструмент впровадження реформ в Украйні [Текст], О. Л. Валевський, В. А. Ребкало, „Аналітика і влада” 2012/6, с. 139-144. 


\section{TRANSFORMATION OF ADMINISTRATIVE GOVERNANCE IN THE CONTEXT OF CURRENT MANAGEMENT PRINCIPLES}

In the article the modern principles of norm-setting activities in the system of public administration are characterized. The current complex of administrative management system was analyzed, as well as the direction of scientific analysis of such systems based on the use of management principles. The theoretical basis of origin, formation and development of complex management systems is developed and systematized. On the basis of the study it was proved that public law regulation of behavior of subjects and objects of management, which is carried out with the help of organizational-legal regulation able to ensure the consistency and purposefulness of their activities, is oriented on satisfaction of public requirements and interests, which objectively exist at a particular stage of social development. It was accented the fact that the European experience of administration of management systems is evidence of the actualization of the normative component of the public administration.

In the article special attention is paid to the contemporary development paradigms of management science. In particular, the focus is on the feasibility of transformation of administrative principles in the context of reforming public administration in Ukraine. On this basis, from the standpoint of system the analysis has shown that public administration provides for the operation of a universal legal mechanism for the identification, coordination and implementation of community needs and interests through the use of various legal means. This, in turn, provides for the formation of a complex of the subjective rights and duties of participants of social processes, their connections and relationships in a particular relationship.

Keywords: decentralization, governance, integrated system of public administration, public relations, management.

DOI: $10.7862 /$ rz.2016.mmr.2

Tekst złożono w redakcji: luty 2016

Przyjęto do druku: maj 2016 